\title{
Genital human papillomavirus lesions of the male sexual partners: the diagnostic accuracy of peniscopy
}

\author{
M Hippeläinen, M Yliskoski, S Saarikoski, S Syrjänen, K Syrjänen
}

\begin{abstract}
Objectives-To evaluate the accuracy of peniscopy for identifying human papillomavirus (HPV) lesions in male sexual partners of women with HPV infection. The predictive value of the medical history for HPV infection was also evaluated.

Design-Examination of voluntary male partners of the women with HPV infection using colposcopy (peniscopy after acetic acid), cytology and surgical biopsy, the latter being analysed by light microscopy, in situ hybridisation (ISH) and polymerase chain reaction (PCR) for HPV DNA. A detailed medical history was to be taken, too.

Setting-Department of Gynaecology and Obstetrics, Kuopio University Central Hospital, Finland.

Subjects-A series of 101 voluntary male partners of 101 women invited for examination, treatment and follow-up for their genital HPV infections on the basis of abnormal Papanicolaou (PAP) smears.

Results-On peniscopy $64(63.4 \%)$ of the men presented with lesions either typical of $(34 \cdot 7 \%)$ or suspicious for $(28 \cdot 7 \%) \mathrm{HPV}$ infection. Of the latter, $89 \%$ were flat lesions mostly undetectable by the naked eye. The cytologic smear was positive in only nine men. On light microscope, $85.7 \%$ of the peniscopically typical lesions were found to be consistent with $(68.6 \%)$ or suspicious for $(17 \cdot 1 \%)$ HPV infection. HPV DNA was found in $33(34.5 \%)$ of the 96 typed biopsies, and never in biopsies from peniscopically healthy areas. In logistic regression analysis of the historical data recorded, only the contact time with the current sexual partner was of predictive value for histologically proven HPV infection.
\end{abstract}

Department of Gynaecology and Obstetrics, University of Kuopio, Finland

M Hippeläinen, M Yliskoski, S Saarikoski

Department of Pathology, University of Kuopio, Finland

S Syrjänen, K Syriänen

Kuopio Cancer Research Centre, University of Kuopio, Finland

K Syrjänen
Conclusions-Peniscopy is an applicable means for the identification of penile lesions due to HPV infection, but it is not a conclusive diagnostic tool capable of differentiating HPV from non-HPV findings.

\section{Introduction}

Human papillomavirus (HPV) is strongly suspected of playing an aetiological role in the pathogenesis of cervical carcinoma, its precursors and other squamous cell lesions of the lower female genital tract and the anus. ${ }^{12}$ The role of male sexual partners in the transmission of HPV infections is highly controversial. This is partly because of our limited understanding of the prevalence of genital HPV infections. Whereas the prevalence of HPVassociated lesions in asymptomatic sexually active men is probably no higher than $10 \%$ in the general population, ${ }^{3}$ the rate of infected male partners of women with condyloma or abnormal cervical smears must be considerably higher, figures around $65 \%$ being reported by some authors. ${ }^{48}$ Baggish ${ }^{9}$ (1982), first noted that $82 \%$ of the male partners of women with recurrent condyloma had penile condylomata, mostly subclinical, which is consistent with the data of some others. ${ }^{1011}$

Accurate diagnosis and proper treatment of male genital HPV infections are issues of considerable importance, because they might be offered to prevent the sequence of events leading to female genital condylomata or squamous neoplasia. ${ }^{12}$ Obviously, this would be especially important for future sexual partners. The male sexual partners of women with condylomata or abnormal cytology are rarely aware of penile lesions, as most of them remain subclinical or latent for a considerable time. ${ }^{3}$ Unfortunately, there are as yet no consistently reliable diagnostic methods available for routine use. During the last few years, examination of the male genitalia by colposcopic equipment after application of $5 \%$ acetic acid has been claimed to be the most reliable method for the identification of subclinical HPV infection..$^{511}$ However, no uniformly accepted colposcopic criteria for the male lesions have been presented so far.

The aim of the present study was to establish the frequency of HPV infection in the male sexual partners of $101 \mathrm{HPV}$-infected women, and to compare the diagnostic accuracy of peniscopic examina- 
tion with cytology, conventional histopathology, and HPV-DNA detection techniques (in situ hybridisation (ISH) and polymerase chain reaction (PCR)). The predictive value of the previous medical history for the male genital warts was also evaluated.

\section{Material and methods Patients}

A series of male sexual partners of 101 women invited for examination, treatment and follow-up for their genital HPV infections (so-called Treatment Group $)^{13}$ on the basis of abnormal Papanicolaou (PAP) smears, volunteered to be examined between February 1989 and February 1990, using colposcopy (peniscopy), cytology, and surgical biopsy. A detailed medical history was taken, including previous sexually transmitted diseases, therapy for condylomata, dermatologic problems, chronic diseases and any therapy known to suppress the immune system, for example, corticosteroids, cytostatics and other immunosuppressants. Information regarding occupation, smoking habits, total number of sexual partners during the last two years, exposure time to the current sexual partners and use of condoms was also requested.

\section{Peniscopy}

Examination of the male genitalia was performed with the patient in a lithotomy position on a standard gynaecology table. The external genitalia were inspected grossly for evidence of visible lesions, and were then soaked for five minutes in $5 \%$ acetic acid. The urethral meatus and the entire external surface of the penis, scrotum, and anus were systematically examined with a colposcope with a magnification of $\times 7-12$. Small surface irregularities, colour differences and changes in vascularisation can be visualised by this magnification. Additional acetic acid was applied during the examination by covering the external genitalia with cotton gauze pads soaked in acetic acid. The distal urethra was inspected with a paediatric nasal speculum. If anal condylomata were present, the anal canal was inspected with a proctoscope. A small surgical biopsy was obtained from one or two representative lesions after subepidermal injection of $1 \%$ lidocaine without epinephrine, using a tuberculin syringe and a 26 -gauge needle. Topical lidocaine jelly was often sufficient for taking a biopsy of urethral lesions. If a second biopsy was permitted by the patient, it was taken from a peniscopically normal area, adjacent to $(1 \mathrm{~cm})$ the biopsied lesion. Cultures from the urethra for other viruses (Herpes simplex, Cytomegalovirus) and Chlamydia trachomatis were performed, as well.

According to the aims of the study (that is, to screen HPV-related lesions by colposcopy) the peniscopic abnormalities were classified into one of the following categories: (1) exophytic, (2) flat or macular or (3) nonspecific lesions (no HPV). ${ }^{510}$ The findings were not always unequivocal, and thus a category of HPV-suggestive lesions was used as well. This was especially true with the evaluation of flat lesions (table 1).

\section{Cytology}

A cytological smear was obtained from the urethra and the penile surface using a moistened swab and a wooden spatula and stained with routine Papanicolaou stain. The smears were evaluated concomitantly with the biopsy (by the same pathologist). Koilocytotic changes were interpreted as conclusive cytologic evidence of HPV infection. ${ }^{14}$

\section{Histology}

The biopsies were fixed in $10 \%$ neutral formalin, embedded in paraffin and processed for light microscopy according to standard procedures. All biopsies were evaluated on light microscopy by a single pathologist (KS), who was aware of the peniscopic findings. The histological criteria used to classify the lesions into papillary, flat or endophytic condylomas have been detailed before ${ }^{14}$ In addition, papulosis, pigmented papulosis and Bowenoid papulosis were recorded using the commonly accepted criteria. ${ }^{15}$ Koilocytosis and superficial cell parakeratosis were the two most reliable signs of HPV infection. The lesion was graded HPV-suggestive if acanthosis or hyperkeratosis were present.

\section{Detection of HPV DNA}

To analyse for the presence of HPV DNA in the paraffin sections, in situ DNA hybridisation with ${ }^{35} \mathrm{~S}-$ or biotin-labelled specific DNA probes for HPV types $6,11,16,18,31,33$ and 42 were utilised, as detailed before ${ }^{16}$ Polymerase chain reaction was used to amplify the HPV DNA in biopsy specimens in which routine ISH remained HPV-negative, but peniscopic or histologic findings were highly consistent with or suspicious for HPV infection.

\section{Table 1 Classification of the peniscopy findings}

\section{Exophytic lesions:}

(a) classic condyloma

(b) papillary (a protrusion papilloma)

(c) papular (a slightly raised lesion in a circumscript area)

(d) PIN-suspicious (Bowenoid papulosis), that is naevus-like pigmented lesion

2. Flat or macular lesions:

(a) typical, a well demarcated, acetowhite lesion at skin level or slightly elevated. Punctuation quite suggestive

(b) suspicious or atypical, a more diffuse acetowhite lesion or a single small papule

(c) PIN-suspicious, a thick, strongly acetowhite or leukoplakic area with groove punctuation

3. Non-specific lesions:

A lesion exhibiting a ragged border, including ulcers, vesicles and naevi 


\section{Statistical methods}

To analyse the correlation between colposcopic and histological findings, Pearson's correlation coefficient was used. The classified variables were compared with the chi-square ${ }^{2}$-test. The power of historical variables for predicting HPV infection was analysed with logistic regression analysis. All calculations were carried out with the SPSS-PC $+v 3 \cdot 1$ computer program.

\section{Results}

One hundred and one men were examined. The mean age was 28.6 years (range 19-45). Of the patients 94 $(93.1 \%)$ were healthy (one man had hypertension, another diabetes and five men had mild allergic symptoms); $61(60.4 \%)$ of them were smokers. Circumcision had been performed on only one man. Altogether, $16(15 \cdot 8 \%)$ gave a history of previous chlamydia and/or gonorrhoea infection (STDs), that is, eight $(20 \%)$ of the males with findings typical for HPV on light microscopy and eight $(13.3 \%)$ of the males without HPV. The difference between these two groups was not significant $\left(\chi^{2}, \operatorname{sig}=0.57\right)$. None of the 101 men was diagnosed with current Chlamydia trachomatis infection, but two had genital herpes (HSV) on examination.

Prior to enrolment in the study, $17 \mathrm{men}$ had received treatment for genital condylomata; (eight laser vaporisation, two cryosurgery, seven podophyllotoxin, and three laser plus podophyllotoxin). At examination, $83(82.2 \%)$ were symptomless, and 18 admitted to some kind of complaint in response to specific questioning. Eight men with recent therapy for condylomata had symptoms including pruritus (two), soreness (three) and small wounds (two). Two other men with small wounds had genital herpes infection. Three men reported occasional haematuria; all three had exophytic urethral condylomata not visible to the naked eye, as did one man with soreness, and two men with pruritus. Three men reporting pruritus had no abnormal findings. Twelve of these 18 males were found to have peniscopically and seven histologically documentable HPV lesions.

The mean contact time with the current sexual partner was $30 \cdot 6$ months (range, $1-180$ months). The total number of sexual partners during the preceding two years varied from one to 21 , (mean $2 \cdot 94$ ). Only 23 $(22 \cdot 8 \%)$ patients admitted to using condoms and only one of them regularly during the preceding two years.

In logistic regression analysis of the historical data recorded, only the contact time with the current sexual partner was of predictive value for histologically proven HPV infection, that is, the shorter the time with the current partner, the greater the probability of finding HPV infection in the male partner.
On gross examination, 10 men $(9.9 \%)$ had an exophytic condylomata, and 12 other men had different kinds of visible lesions, including papules (five), erythematous epithelium (12), herpes lesions (one), and ulcers, naevi, vesicles, etc (seven).

On peniscopy, $90 \%$ of the men presented with an abnormal pattern, $26.6 \%$ with nonspecific lesions (no HPV), and $63.4 \%$ with lesions either typical of $(34.7 \%)$ or suspicious for $(28.7 \%)$ HPV infection. Of the latter, $89 \%$ were flat lesions. Of the males with findings related to HPV infection, 33/64 $(51 \cdot 6 \%)$ had lesions of a single morphology (table 2).

The localisation of the peniscopic lesions is summarised in table 3. Involvement of multuple sites was a notably frequent event. Most lesions associated with HPV were found on the preputium, at the frenulum and on the penile shaft (table 4).

The cytologic smear obtained from the urethra or

Table 2 Type of peniscopy findings in 64 males with typical or suspicious HPV lesions

\begin{tabular}{lcc}
\hline $\begin{array}{l}\text { Peniscopic } \\
\text { appearance }\end{array}$ & $\begin{array}{l}\text { Number of } \\
\text { cases }\end{array}$ & $\begin{array}{l}\text { Per cent } \\
\text { of cases }\end{array}$ \\
\hline 1. Exophytic & & \\
Condylom acc. & 10 & $15 \cdot 6$ \\
Papilloma & 3 & $4 \cdot 6$ \\
Papules & 12 & $18 \cdot 7$ \\
2. Flat & 57 & $89 \cdot 0$ \\
3. Non-specific & 7 & $10 \cdot 9$ \\
Herpes & 2 & $3 \cdot 1$ \\
4. PIN-suspicious & 7 & 10.9 \\
Single lesions & 33 & $51 \cdot 6$ \\
Mixed lesions & 31 & 48.4 \\
$\quad$ Two distinct & 27 & 42.2 \\
Three distinct & 3 & 4.6 \\
Four distinct & 1 & 1.6 \\
\hline
\end{tabular}

Table 3 Location of peniscopy lesions in 64 males with suspected HPV infection

\begin{tabular}{|c|c|c|c|c|}
\hline \multirow{3}{*}{$\begin{array}{l}\text { Site of } \\
\text { lesion }\end{array}$} & \multirow{2}{*}{\multicolumn{2}{|c|}{$\frac{\text { At this site only }}{\text { Patients }}$}} & \multirow{2}{*}{\multicolumn{2}{|c|}{$\begin{array}{l}\text { At this and other sites } \\
\text { Patients }\end{array}$}} \\
\hline & & & & \\
\hline & No & Per cent & No & Per cent \\
\hline $\begin{array}{l}\text { Meatus } \\
\text { Glans } \\
\text { Sulcus } \\
\text { Preputium } \\
\text { Frenulum } \\
\text { Shaft } \\
\text { Scrotum } \\
\text { Anus/perineum } \\
\text { Groins }\end{array}$ & $\begin{array}{l}2 \\
0 \\
0 \\
4 \\
5 \\
4 \\
0 \\
0 \\
0\end{array}$ & $\begin{array}{l}6 \cdot 3 \\
7 \cdot 8 \\
6 \cdot 3\end{array}$ & $\begin{array}{r}14 \\
13 \\
13 \\
39 \\
31 \\
25 \\
7 \\
5 \\
5\end{array}$ & $\begin{array}{r}21 \cdot 8 \\
20 \cdot 3 \\
20 \cdot 3 \\
60 \cdot 9 \\
48 \cdot 4 \\
39 \cdot 0 \\
10 \cdot 9 \\
7 \cdot 8 \\
7 \cdot 8\end{array}$ \\
\hline \multirow{2}{*}{$\begin{array}{l}\text { Number } \\
\text { of sites }\end{array}$} & \multicolumn{2}{|c|}{ Patients } & & \\
\hline & No & Per cent & & \\
\hline $\begin{array}{l}1 \\
2 \\
3 \\
4 \\
5 \\
6 \\
\text { Total }\end{array}$ & $\begin{array}{r}15 \\
29 \\
16 \\
3 \\
0 \\
1 \\
64\end{array}$ & $\begin{array}{r}23 \cdot 4 \\
45 \cdot 3 \\
25 \cdot 0 \\
4 \cdot 7 \\
0 \cdot 0 \\
1 \cdot 6 \\
100 \cdot 0\end{array}$ & & \\
\hline
\end{tabular}


Table 4 Location of HPV lesions on peniscopy according to lesion type

\begin{tabular}{|c|c|c|c|c|c|c|c|c|c|}
\hline \multirow{2}{*}{$\begin{array}{l}\text { HPV } \\
\text { Peniscopy }\end{array}$} & \multicolumn{9}{|c|}{ No of patients with lesions at each location } \\
\hline & Meatus & Glans & Sulcus & Prep. & Frenul. & Shaft & Scrot. & Anus & Groins \\
\hline $\begin{array}{l}\text { Exoph. } \\
\text { Flat } \\
\text { PIN? } \\
\text { Total }\end{array}$ & $\begin{array}{r}3 \\
9 \\
0 \\
12\end{array}$ & $\begin{array}{r}0 \\
9 \\
1 \\
10\end{array}$ & $\begin{array}{r}6 \\
6 \\
0 \\
12\end{array}$ & $\begin{array}{r}5 \\
28 \\
4 \\
37\end{array}$ & $\begin{array}{r}0 \\
23 \\
3 \\
26\end{array}$ & $\begin{array}{r}11 \\
12 \\
3 \\
26\end{array}$ & $\begin{array}{l}0 \\
7 \\
0 \\
7\end{array}$ & $\begin{array}{l}0 \\
4 \\
0 \\
4\end{array}$ & $\begin{array}{l}2 \\
0 \\
0 \\
2\end{array}$ \\
\hline
\end{tabular}

Table 5 Cross-tabulation of light microscopy and peniscopy findings

\begin{tabular}{|c|c|c|c|c|}
\hline \multirow[b]{2}{*}{ Light microscopy } & \multicolumn{3}{|l|}{ Peniscopy findings } & \multirow[b]{2}{*}{ Row total } \\
\hline & Non-specific no HPV & Suspicious & Typical & \\
\hline $\begin{array}{l}\text { Non-specific } \\
\text { no HPV } \\
\% \\
\text { Suspicious } \\
\% \\
\text { Typical } \\
\% \\
\text { Column } \\
\text { Total }\end{array}$ & $\begin{array}{l}30 \\
81 \cdot 1 \% \\
3 \\
8 \cdot 1 \% \\
4 \\
10 \cdot 8 \% \\
37 \\
36 \cdot 6 \%\end{array}$ & $\begin{array}{l}8 \\
27 \cdot 6 \% \\
8 \\
27 \cdot 6 \% \\
13 \\
44 \cdot 8 \% \\
29 \\
28 \cdot 7 \%\end{array}$ & $\begin{array}{l}5 \\
14 \cdot 3 \% \\
6 \\
17 \cdot 1 \% \\
24 \\
68 \cdot 6 \% \\
35 \\
34 \cdot 7 \%\end{array}$ & $\begin{array}{l}43 \\
42 \cdot 6 \% \\
17 \\
16 \cdot 8 \% \\
41 \\
40 \cdot 6 \% \\
101 \\
100 \%\end{array}$ \\
\hline
\end{tabular}

from the penile epithelium was positive in nine of the 101 men (that is koilocytes were found).

Altogether, 164 biopsies were analysed from the 101 men, 63 being from peniscopically normal epithelium at a distance of $1 \mathrm{~cm}$ from the lesion. Thus, all kinds of lesions were not biopsied because of unwillingness of the men. On light microscopy, $85 \cdot 7 \%$ of the peniscopically typical lesions were found to be consistent with $(68 \cdot 6 \%)$ or suspicious for $(17 \cdot 1 \%)$ HPV infection. Biopsies from five men with peniscopically typical findings $(14.3 \%)$ did not show histological HPV infection. Two of these men actually had exophytic condylomata; however, the biopsy specimens were taken from flat lesions on the preputium and were too small to analyse reliably, and no HPV was seen. Three of these men had flat, well demarcated acetowhite lesions on the prepuce and one on the glans; however, the histological diagnosis was nonspecific hyperkeratosis. Thirteen $(44.8 \%)$ of peniscopically suspicious and four $(10.8 \%)$ of nonspecific lesions showed a pattern for HPV infection; of the latter lesions, all were flat, weakly acetowhite and not very well demarcated, and were thus graded as nonspecific lesions by the peniscopist. PIN was present in $5 \%$ of the males. On the other hand no biopsy (64) from peniscopically normal areas showed HPV infection.

The correlation between classification based on peniscopy and on light microscopy was statistically significant, Pearson's correlation coefficient 0.57 (p $<$ 0.001 ) (table 5).

HPV DNA was found by ISH in $33(34.4 \%)$ of the 96 typed biopsies. PCR amplification increased the detection of HPV DNA by only one case. HPV DNA was never found by either of the two techniques in biopsies from peniscopically healthy areas (table 6). Fifty one per cent of typical peniscopic lesions revealed HPV-DNA. Interestingly, in peniscopically suspicious lesions, HPV-DNA was found in 55.6\%. Likewise, in biopsies exhibiting a typical or suspicious finding on light microscopy, HPV DNA was detected in $53.7 \%$ and $58.8 \%$, respectively (table 7 ).

Table 6 Correlation between HPV-DNA detection and peniscopy in 96 males

\begin{tabular}{lcllll}
\hline & \multicolumn{2}{l}{$H P V-D N A$} \\
\cline { 2 - 3 } & \multicolumn{2}{l}{ Positive } & & \multicolumn{2}{l}{ Negative } \\
\cline { 2 - 3 } \cline { 5 - 6 } Peniscopy & No & Per cent & & No & Per cent \\
\hline Typical & 18 & 51.4 & & 17 & 48.6 \\
Suspicious & 15 & 55.6 & & 12 & 44.4 \\
Non-specific/no HPV & 0 & 0 & & 34 & 100.0 \\
Total & 33 & 34.4 & & 63 & 65.6 \\
\hline
\end{tabular}

Table 7 Correlation between HPV-DNA detection and histology in 96 males

\begin{tabular}{|c|c|c|c|c|}
\hline \multirow[b]{3}{*}{ Histology } & \multicolumn{4}{|c|}{$H P V-D N A$} \\
\hline & \multicolumn{2}{|c|}{ Positive } & \multicolumn{2}{|c|}{ Negative } \\
\hline & No & Per cent & No & Per cent \\
\hline $\begin{array}{l}\text { Typical } \\
\text { Suspicious } \\
\text { Non-specific/no HPV } \\
\text { Total }\end{array}$ & $\begin{array}{r}22 \\
10 \\
2 \\
34\end{array}$ & $\begin{array}{r}53 \cdot 7 \\
58 \cdot 8 \\
4 \cdot 6 \\
35 \cdot 4\end{array}$ & $\begin{array}{r}19 \\
7 \\
36 \\
62\end{array}$ & $\begin{array}{l}46 \cdot 3 \\
41 \cdot 2 \\
95 \cdot 4 \\
64 \cdot 5\end{array}$ \\
\hline
\end{tabular}




\section{Discussion}

Since the first report of Baggish, ${ }^{9}$ special attention has been paid to the role of the male sexual partner in transmitting HPV and to the importance of the male factor in the aetiology of female lower genital tract neoplasia. ${ }^{1}$ The risk factors for genital HPV infections in men have not been extensively studied. In logistic regression analysis, the contact time with the current sexual partner proved to be the only predictive historical factor for HPV infection in the 101 mostly symptomless male partners in this study. This is a perplexing finding. All the men were partners of women with recently detected HPV infection. It might be that HPV infections in the men with longer contact times could have regressed spontaneously. It can also be speculated that the males could have been infected by the women. HPV infection is often associated with other STDs, according to previous reports. ${ }^{361017}$ However, in this study logistic regression analysis did not show a history of STDs to be predictive for genital HPV. Surprisingly, none of our patients was found to have those diseases at the examination. This is an indication of the effective tracing and treatment policy for these infections in our country. The rather weak symptoms of 18 men $(17.8 \%)$ were obviously due to previous therapy for condylomata or for urethral HPV infection; lesions at other sites were symptomless.

Several studies have confirmed the important role of peniscopic examination in the diagnosis of HPV lesions on the male external genitalia..$^{6-810-12}$ This view is clearly substantiated by the present results. When using histology as the standard for identification of HPV infection, the accuracy of peniscopy was acceptable (correlation coefficient 0.57). In the present series of 101 male partners of women with established genital HPV infections, the $63.1 \%$ prevalence of positive peniscopy is in agreement with the previous studies. ${ }^{56}$

The accuracy of peniscopy is naturally dependent on the morphology of the findings. Classical condylomata were easily identified also by the naked eye. Other slightly elevated lesions presenting as punctate vessels and/or small papules could have been clinically missed because of their small size. Histologically, some papillary proliferations can resemble classical condyloma, and small well demarcated papules which stain strongly after the application of acetic acid may be classified as flat condylomas ${ }^{6}$ or nonspecific inflammation, especially when solitary.

The correct assessment of flat lesions was the most problematic issue because of the variety of factors responsible for acetowhite staining: nonspecific infections, healing areas after treatment, etc. The majority of flat lesions were invisible before acetic acid application. The size of acetowhite flat lesions varied from $1-2 \mathrm{~mm}$ to $1-2 \mathrm{~cm}$, and they usually appeared in small groups or confluent plaques, as described by some other authors. ${ }^{1012}$ In the present study, four of the six PIN lesions were suspected peniscopically. Two were well demarcated, elevated plaques of 1 $2 \mathrm{~cm}$, seen also macroscopically as reddish, slightly elevated macules. They stained strongly after acetic acid, and punctate (capillary loops) were seen very clearly. The other two were classified as Bowenoid papulosis, and were papular, naevus-like, pigmented lesions, which remained acetic acid-negative.

To summarise, $89 \%$ of the peniscopic findings suspicious for HPV infection were flat or macular acetowhite lesions. Most of them were found at sites subjected to epithelial trauma during intercourse, that is, prepuce and frenulum. Such an association has been reported by many other authors as well. ${ }^{46}$ When HPV lesions at different sites were analysed, we could clearly confirm the multifocal nature of HPV infection in the male genitalia. This was true only with the HPV lesions on the penile epithelium. In $11.9 \%$ of the males in our study, HPV lesions in the distal urethra were detected only by speculum. Surprisingly, most of the lesions $(75 \%)$ were flat. The diagnostic accuracy of peniscopy was highest in the screening of lesions located at the urethral meatus and distal urethra. All men with peniscopically detected HPV lesions had HPV infection confirmed on light microscopy, and in $75 \%$, HPV DNA was found as well. It can be speculated that experience and training in the use of peniscopy could further improve the diagnostic accuracy of this technique.

In theory, the cytological smear should be the most convenient means for diagnosis of genital HPV infection in the male as it is in the female. It is noninvasive, allows the sampling of large areas and may be repeated without difficulty if necessary. Unfortunately, however, only cell samples taken from mucosal surfaces are diagnostically useful. This is because smears from kerantinising squamous epithelia are usually scanty and contain only anucleate squames, which are difficult or impossible to interpret. ${ }^{5}$ This view is also clearly supported by the experience of the present series, where all smears from the external genitalia and many of those from the urethra were unsatisfactory. Thus, koilocytotic cells diagnostic for HPV were found in only $8 \%$ of the sampled males. This represents only $25 \%$ of the patients in whom an HPV lesion was found in the distal urethra by colposcopy and/or histology. Obviously, cell sampling from the urethra with different techniques, such as using a cytobrush, could yield more abundant samples. ${ }^{18}$

Using the conventional histological criteria, ${ }^{14}$ $57.4 \%$ of the biopsy specimens showed features of HPV infection, which represents $80 \%$ of the peniscopically suspected lesions. This figure might have been higher if more biopsies had been performed on the different types of lesions disclosed on peniscopy. 
The histologic diagnosis relies on the cytopathic effect of the virus on the epithelium. It is generally admitted, however, that in the male genitalia the histological features are extremely variable and often difficult to interpret. ${ }^{5}$ In the present study $71 \%$ of the histological findings were quite consistent with HPV infection. Peniscopic overdiagnosis is the rule when biopsies are evaluated on light microscopy. ${ }^{10}$ On the other hand, HPV infections were not disclosed on light microscopy in biopsies from peniscopically healthy areas.

At least in theory, highly sensitive DNA techniques (ISH, PCR) could be used to detect subclinical and latent HPV infection in epithelium that appears normal on gross, peniscopic, cytologic and histologic examination. ${ }^{19-22}$ In our study, 63 biopsies were taken from peniscopically normal epithelium, approximately $1 \mathrm{~cm}$ distant to the suspected HPV lesion, and HPV DNA was never found by ISH.

HPV DNA was found with equal frequency (about $50 \%$ ) from peniscopically typical and HPV-suspicious areas. The correlation between histology and DNA hybridisation was of the same order. The use of PCR increased the detection rate by only one case. The detection rate for HPV DNA seemed to be somewhat lower than that obtained in cervical or vaginal biopsies of clinically manifest HPV lesions. ${ }^{23}$ On the other hand, the DNA detection rate was substantially higher than that for subclinical HPV infection in the female genital tract. ${ }^{24}$ The reasons for such differences might be either one or all of the following: (1) The penile lesions contained HPV types other than those included in the test panel; (2) HPV 42 was included in the panel at a later stage of the study; (3) Biopsies were not taken from the most representative areas; (4) the DNA content was below the detection limits of ISH. Which of these factors are most significant may be clarified when all the biopsies have been analysed by PCR.

To conclude, peniscopy is an applicable means of finding penile lesions due to HPV infection. HPV infections were not disclosed on light microscopy in biopsies from peniscopically healthy areas, nor was HPV DNA found. However, peniscopy is not a conclusive diagnostic tool capable of differentiating HPV from non-HPV findings. With the exception of exophytic condylomata, we are not able at this stage to establish completely reliable criteria for peniscopy. At the present time, no single test used alone can detect all HPV infections. At best, these three techniques (peniscopy, biopsy and HPV typing) are complementary to each other. The cytologic smear is inadequate with the technique we used.

More data are needed about the risk factors for genital infections in men and the significance of male sexual partners in the pathogenesis of squamous cell tumours of the female genital tract.

Address for correspondence: Dr Maritta Hippeläinen, $M D$, Department of Gynecology \& Obstetrics, Kuopio University Central Hospital, SF-70210 Kuopio, Finland.
1 Campion MJ, Singer A, Clarkson PK, McCance DJ. Increased risk of cervical neoplasia in consorts of men with penile condylomata acuminata. Lancet 1985;1:943-6.

2 Nash JD, Burke TW, Hoskins WJ. Biologic course of cervical human papillomavirus infection. Obstet Gynecol 1987;69: 160-9.

3 Stone K. Epidemiologic aspects of genital HPV infection. Clinic Obstet Gynecol 1989;32:112-6.

4 Barrasso R, De Brux J, Croissant O, Orth G. High prevalence of papillomavirus associated penile intraepithelial neoplasia in sexual partners of women with cervical intraepithelial neoplasia. N Engl J Med 1987;317:916-23.

$5 \mathrm{Krebs}$ HB, Schneider V. Human papillomavirus associated lesions of the penis: colposcopy, cytology and histology. Obstet Gynecol 1987;70:299-304.

6 Levine RU, Crum CP, Herman E, Silvers D, Ferenczy A, Richardt $M$. Cervical papillomavirus infection and intraepithelial neoplasia: A study of male sexual partners. Obstet Gynecol 1984;64:16-20.

7 Rosenberg SK, Reid R. Sexually transmitted papillomaviral infections in the male: I Anatomic distribution and clinical features. Urology 1987;24:488-92.

8 Sand PD, Bowen LW, Blischke SO, Ostergard DR. Evaluation of male consorts of women with genital human papillomavirus infection. Obstet Gynecol 1986;68:679-82.

9 Baggish MS. Treating viral venereal infections with the $\mathrm{CO}_{2}$ laser. J Reprod Med 1982;27:737-42.

10 Kennedy L, Buntine DW, O'Connor D, Frazer IH. Human papillomavirus- a study of male sexual partners. Med J Aus 1988;149:309-11.

11 Sedlacek TV, Cunnane M, Carpiniello V. Colposcopy in the diagnosis of penile condyloma. Am J Obstet Gynecol 1986;154:494-6.

$12 \mathrm{Krebs} \mathrm{HB}$. Genital HPV infections in men. Clinic Obstet Gynaecol 1989;32:180-90.

13 Yliskoski M, Saarikoski S, Syrjänen K, Syrjänen S, Castren O. Cryotherapy and $\mathrm{CO}_{2}$-laser vaporization in the treatment of cervical and vaginal human papillomavirus (HPV) infections. Acta Obstet Gynecol Scand 1989;68:619-25.

14 Syrjänen $K$. Papillomavirus infections and the cancer. In: Syrjänen K, Gissman L, Koss LG, eds. Papillomaviruses and Human Disease. Heidelberg: Springer-Verlag, 1987:467-503.

15 Gross G. Lesions of the male and female external genitalia associated with human papillomavirus. In: Syrjänen $K$, Gissman L, Koss LG, eds. Papillomaviruses and Human Disease. Heidelberg: Springer-Verlag, 1987:197-234.

16 Syrjänen S, Syrjänen K. An improved in situ DNA hybridization protocol for detection of human papillomavirus (HPV) DNA sequences in paraffin-embedded biopsies. $J$ Virol Meth 1986;14:293-304.

17 Bistoletti P, Lidbrink P. Sexually transmitted diseases including genital papillomavirus infection in the male sexual partners of women treated for cervical intraepithelial neoplasia III by conization. Br J Obstet Gynaecol 1988;95:611-3.

18 Eriksson MBE, Claesson U, Kataoka A, Lindh E, Wikström K. Detection of HPV in urogenital specimens from Swedish army conscripts. In: Supplement, $7 \mathrm{th}$ World Congress of Cervical Pathology and Colposcopy, Rome, May 13-17, 1990:FC/249.

19 Campion MJ, McCance DJ, Mitchell HS, Jenkins D, Singer A. Subclinical penile human papillomavirus infection and dysplasia in consorts of women with cervical neoplasia. Genitourin Med 1988;64:90-9.

20 Ferenczy A, Mitao M, Nobutaka N, Silverstein SJ, Crum CP. Latent papillomavirus and recurring genital warts. $N$ Engl $j$ Med 1985;313:784-8.

21 Macnab JCM, Alkinshaw SA, Cordiner JW, Clements JB. Human papillomavirus in clinically and histologically normal tissue of patients with genital cancer. $N$ Engl J Med 1986;315:1952-8.

22 Somogyi L, Malpica CC. Carbon dioxide laser treatment of male external genitalia with human papillomavirus (HPV) infection. Colposcopy and Gynecologic Laser Surgery 1986;2: 209-16.

$23 \mathrm{Ji}$ HX, Syrjänen S, Matinlompolo T, Huovinen K, Chang FJ, Syrjänen $K$. Subclinical human papillomavirus infections in the lower female genital tract: histological evaluation and detection of human papillomavirus DNA by in situ hybridization with biotinylated probes. Cervix and Lower Female Genital Tract 1989;7:255-66.

24 Syrjänen S, Saastamoinen J, Chang FJ, Ji HX, Syrjänen K. Colposcopy, punch biopsy, in situ DNA hybridization, and the polymerase chain reaction in searching for genital human papillomavirus (HPV) infections in women with normal PAP smears. J Med Virol 1990;31:259-66.

Accepted for publication 15 April 1991 